\title{
Improved GaN-based HEMT Performance by Nanocrystalline Diamond Capping
}

\author{
T.J. Anderson , K.D. Hobart', M.J. Tadjer, T.I. Feygelson , E.A. Imhoff, D.J. Meyer , D.S. \\ Katzer , J.K. Hite , F.J. Kub , B.B. Pate, S.C. Binari , and C.R. Eddy, Jr
}

As a wide-bandgap semiconductor, gallium nitride $(\mathrm{GaN})$ is an attractive material for next-generation power devices. To date, the capabilities of GaN-based high electron mobility transistors (HEMTs) have been limited by self-heating effects (drain current decreases due to phonon scattering-induced carrier velocity reductions at high drain fields). Despite awareness of this, attempts to mitigate thermal impairment have been limited due to the difficulties involved with placing high thermal conductivity materials close to heat sources in the device. Heat spreading schemes have involved growth of $\mathrm{AlGaN} / \mathrm{GaN}$ on single crystal or CVD diamond, or capping of fullyprocessed HEMTs using nanocrystalline diamond (NCD). All approaches have suffered from reduced HEMT performance or limited substrate size. Recently, a "gate after diamond" approach, shown in Figure 1, has been successfully demonstrated to improve the thermal budget of the process by depositing NCD before the thermally sensitive Schottky gate and also to enable large-area diamond implementation [1].

The "gate after diamond" approach employs the deposition of the diamond heat spreading layer on either the bare $\mathrm{AlGaN}$ surface or a thin nucleation dielectric/passivation layer (eg. $10 \mathrm{~nm} \mathrm{PECVD} \mathrm{SiN} \mathrm{X}_{\mathrm{X}}$ ) after completion of the mesa and ohmic processes, but before the gate metal step. An $\mathrm{O}_{2}$-based plasma etch is used to recess etch the diamond in the gate region before metal deposition. A reference HEMT was fabricated from the same wafer, and was passivated with $100 \mathrm{~nm}$ PECVD $\mathrm{SiN}_{\mathrm{X}}$ in the same process sequence as the NCD-capped device ("gate after nitride"). Hall measurements on van der Pauw structures were used to monitor the 2DEG throughout the fabrication processes to ensure that NCD deposition and processing were not damaging the device. The results are summarized in Table I, with the "covered" and "etched" terminology referring to the van der Pauw patterns that either remained coated with $\mathrm{NCD}$ (or $\mathrm{SiN}_{\mathrm{X}}$ ) or were exposed to the gate recess etch. Based on these results, it is clear that both the diamond deposition and gate recess processes had minimal impact on the 2DEG. The data shown are from $\mathrm{AlGaN} / \mathrm{GaN}$ HEMT structures on $\mathrm{SiC}$ substrates, though the process is currently being extended to InAlN/GaN heterostructures.

Electrical characterization of a NCD-capped device has yielded device performance that is comparable to the non-capped reference device, as shown in Figure 2(a) and (b). The diamond-capped device appeared to demonstrate improved DC I-V characteristics in most key performance areas, as indicated in Table II. Of particular importance are the improved on-resistance, saturation current, and transconductance, and reduced off-state current and gate leakage, which are significant performance metrics for power switches. Furthermore, diamond-capped devices demonstrated improved forward blocking characteristics, manifested by the reduced off-state leakage current and a nearly $200 \mathrm{~V}$ improvement in breakdown voltage in forward blocking mode, as shown in Figure 2(c). RF devices with $3 \mu \mathrm{m}$ source-drain spacing were also fabricated, which yielded small signal $f_{\mathrm{T}}=6 \mathrm{GHz}$ and $f_{\mathrm{MAX}}=23 \mathrm{GHz}$ for a $1.5 \mu \mathrm{m}$ gate length device

Electroluminescence (EL) imaging, shown in Figure 3, was used to gain some insight into the breakdown performance of these devices. At low bias conditions, a more intense emission was observed in NCD-capped devices despite the lower gate and drain leakage currents were lower. Experiments are in-progress to quantify the nature of this emission, however this result implies that the emission is related to the heat or field-spreading effects of the diamond layer. This work was supported by NRL and ONR (P. Maki).

[1] M.J. Tadjer, T.J. Anderson, K.D. Hobart, T.I. Feygelson, J.D. Caldwell, C.R. Eddy, Jr, F.J. Kub, J.E. Butler, B.B. Pate, J. Melngailis, 'Reduced self-heating in AlGaN/GaN HEMTs Using Nanocrystalline Diamond Heat Spreading Films." IEEE Electron Dev. Lett. Vol. 33, No. 1, 23-25 (2012) 

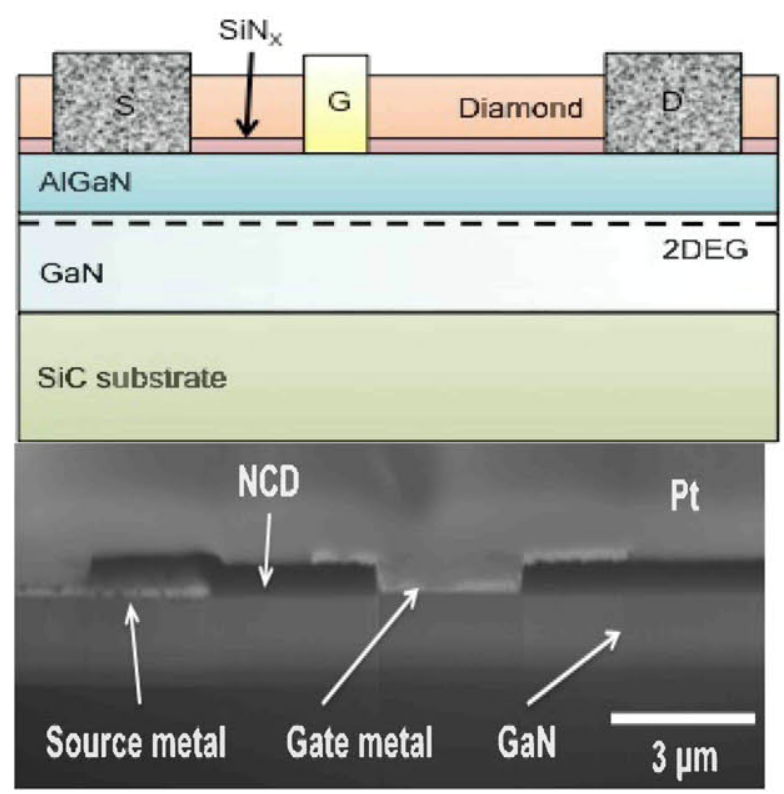

Figure 1. Schematic and FIB cross section of diamond-capped $\mathrm{AlGaN} / \mathrm{GaN}$ HEMT. Pt was deposited in the FIB to protect the surface during ion milling.
Table I: Hall data for reference and diamond-capped HEMTs

\begin{tabular}{|l|l|c|c|c|}
\hline \multicolumn{2}{|c|}{} & $\mathrm{R}_{\mathrm{SH}}(\Omega / \square)$ & $\mu\left(\mathrm{cm}^{2} / \mathrm{V}-\mathrm{s}\right)$ & $\mathrm{N}_{\mathrm{SH}}\left(\mathrm{cm}^{-2}\right)$ \\
\hline \multirow{2}{*}{$\begin{array}{l}\text { NCD before } \\
\text { gate HEMT }\end{array}$} & covered & 488 & 1260 & $1.02 \times 10^{13}$ \\
\cline { 2 - 5 } & etched & 478 & 1280 & $1.02 \times 10^{13}$ \\
\hline \multirow{2}{*}{$\begin{array}{l}\text { Reference } \\
\text { HEMT }\end{array}$} & covered & 574 & 1270 & $9.22 \times 10^{12}$ \\
\cline { 2 - 5 } & etched & 533 & 1220 & $8.92 \times 10^{12}$ \\
\hline
\end{tabular}

Table II: Device performance metrics for reference and diamond-capped HEMTs

\begin{tabular}{|l|c|c|l|l|c|}
\hline & $\begin{array}{l}R_{\text {ON }} \\
(\Omega-m m)\end{array}$ & $\begin{array}{l}I_{S \mathrm{~S}} \\
(\mathrm{~A} / \mathrm{mm})\end{array}$ & $\begin{array}{l}\mathrm{I}_{\text {OFF }} \\
(\mathrm{A} / \mathrm{mm})\end{array}$ & $V_{T}$ & $\begin{array}{l}g_{\max } \\
(\mathrm{S} / \mathrm{mm})\end{array}$ \\
\hline $\begin{array}{l}\text { NCD before } \\
\text { gate HEMT }\end{array}$ & 11.9 & 0.445 & $1.0 \times 10^{-5}$ & -3.36 & 0.127 \\
\hline $\begin{array}{l}\text { Reference } \\
\text { HEMT }\end{array}$ & 14.6 & 0.380 & $9.5 \times 10^{-5}$ & -3.07 & 0.114 \\
\hline
\end{tabular}
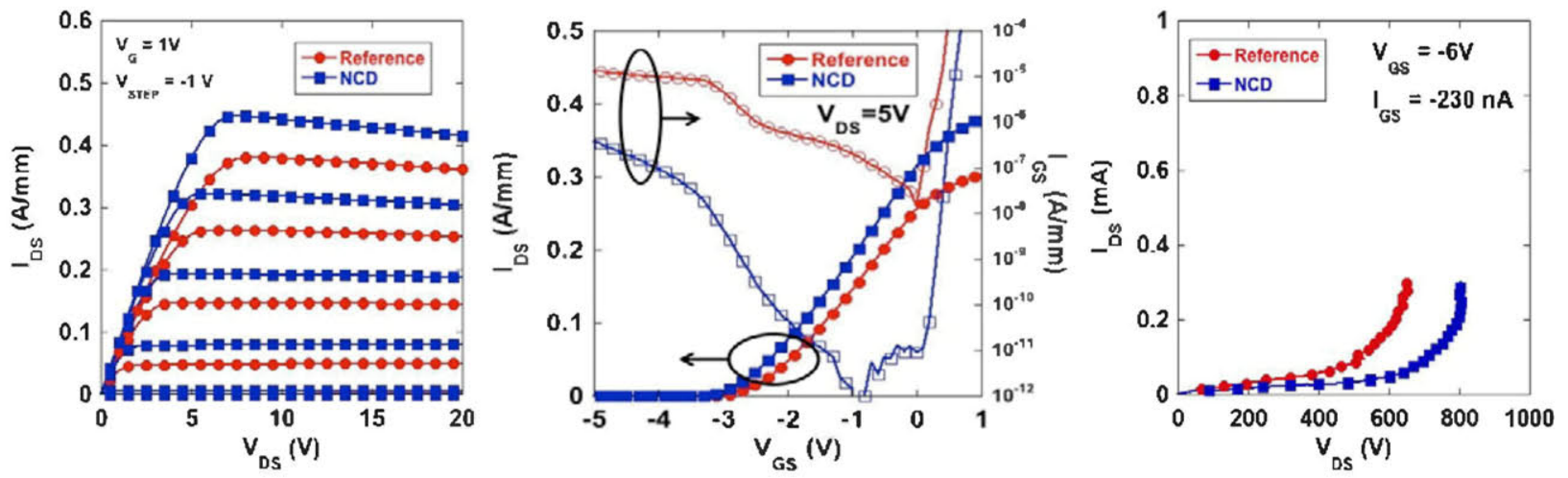

Figure 2. a) $V_{G}-I_{D S}$ curves, b) $V_{D S}-I_{D S}$ curves, and c) forward blocking characteristics for reference and diamond-capped devices
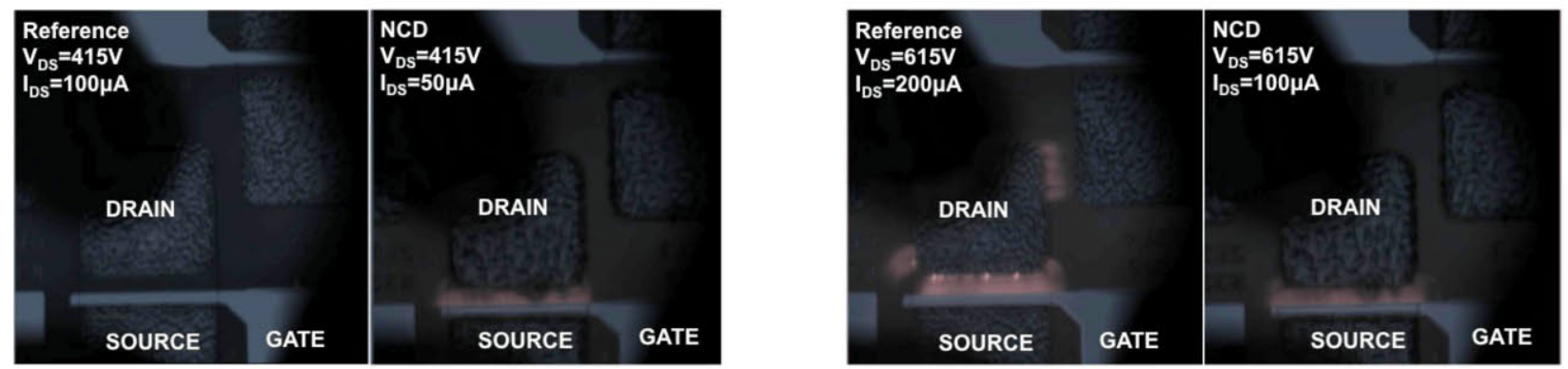

Figure 3. False-color EL images of reference and diamond-capped devices at $\mathrm{V}_{\mathrm{DS}}=415 \mathrm{~V}$ and $615 \mathrm{~V}$. $\mathrm{V}_{\mathrm{GS}}=-6 \mathrm{~V}$ in all images. 